\title{
ANALISIS PENGARUH KUALITAS PELAYANAN TERHADAP KEPUASAN MASYARAKAT DALAM PEMBUATAN KTP DI DINAS KEPENDUDUKAN DAN PENCATATAN SIPIL KOTA LANGSA
}

\author{
Suci Wardani ${ }^{1}$, Riezky Purnama Sari \\ ${ }^{1,2}$ Program Studi Matematika, Fakultas Teknik Universitas Samudra \\ email :'Wardanisuci3@gmail.com, ${ }^{2}$ riezkypurnamasari@gmail.com
}

\begin{abstract}
ABSTRAK
Kualitas Pelayanan merupakan perbandingan antara kenyataan atas pelayanan yang diterima dengan harapan atas pelayanan yang ingin diterima. Penyelenggaraan pelayanan publik di Indonesia menjadi tanggungjawab pemerintah yang merupakan amanat dari undang-Undang Dasar 1945 yang secara yuridis diatur dalam pasal 34 ayat (3) dan untuk kepastian hukum terkait pelayanan publik. Salah satu bentuk penyelenggaraan pelayanan publik pemerintah kepada masyarakat adalah pelayanan Kartu Tanda Penduduk Elektronik (KTP-el) yang berkaitan dengan administrasi kependudukan dan pencatatan sipil.Penelitian ini menggunakan metode regresi linear berganda, variabel terikat dari penelitian ini adalah variable $X_{1}, X_{2}, X_{3} X_{4}$ dan variable tidak bebas yaitu Y.Instrumen yang digunakan dalam penelitian ini berupa angket atau kuesioner yang dibagikan kepada 45 responden. Teknik pengumpulan data yang digunakan dalam penelitian ini adalah dengan cara membagikan kuesioner kepada responden yang sudah mempunyai KTP yang terdiri atas 21 pertanyaan dengan skala likertnya Sangat Tidak Baik $=1$, Tidak Baik $=2$, Cukup Baik $=3$, Baik = 4, Sangat Baik $=5$. Dari analisis, di dapat koefisien determinasi sebesar 0,396. Artinya bahwa 39,6\% variabel Kepuasan masyarakat akan dipengaruhi oleh variabel kualitas pelayanan. Sedangkan sisanya 60,4\% variabel Kepuasan masyarakat akan dipengaruhi oleh variabel-variabel yang lain yang tidak dibahas dalam penelitian ini. Selain koefisien determinasi juga di dapat koefisien korelasi (R) sebesar 0,630. Kualitas pelayanan yang terdiri dari realibilitas dan empati secara simultan berpengaruh terhadap kepuasan masyarakat yang menerima pelayanan perekaman KTP. Sedangkan tangible dan responsiveness secara simultan tidak berpengaruh terhadap kepuasan masyarakat yang menerima pelayanan perekaman KTP.
\end{abstract}

\section{Kata kunci : Kualitas Pelayanan, Uji regresi berganda, Kepuasan Masyarakat}

\section{PENDAHULUAN}

Sejak merdeka indonesia belum pernah mengalami peninjauan untuk diubah/ disesuaikan dengan perkembangan hukum dalam masyarakat. Kemudian atas dasar Instruksi Presidum Kabinet Ampera Nomor 31/U/IN/12/1996 tanggal 27 Desember 1966, membawa perkembangan baru bagi dunia dan catatan sipil di Indonesia.

Kantor catatan Sipil diseluruh Indonesia dinyatakan terbuka bagi seluruh penduduk. Peraturan catatan sipil berkembang lebih lanjut dengan dikeluarkannya keputusan Presiden Nomor 12 tahun 1983 Tentang Penataan dan Peningkatan Pembinaan Penyelenggaraan Catatan Sipil dengan melakukan pembaharuan kantor catatan sipil sampai ke kota madya/ kabupaten daerah tingkat II seluruh Indonesia.

Penyelenggaraan pelayanan publik di Indonesia menjadi tanggungjawab pemerintah yang merupakan amanat dari undang-Undang Dasar 1945 yang secara yuridis diatur dalam pasal 34 ayat (3) dan untuk kepastian hukum terkait pelayanan publik. Salah satu bentuk penyelenggaraan pelayanan publik pemerintah kepada masyarakat adalah pelayanan Kartu Tanda Penduduk Elektronik (KTP- el) yang berkaitan dengan administrasi kependudukan dan pencatatan sipil.

Diberlakukannya KTP-el di Indonesia karena KTP lama/konvensional rentan akan duplikasi dan manipulasi data kependudukan sehingga seseorang dapat memiliki leboih dari 1 (satu) KTP. Diberlakukannya KTP-el, Penduduk hanya diperbolehkan memiliki 1 (satu) KTP-el yang tercantum Nomor Induk Kependudukan (NIK).

Kualitas Pelayanan merupakan perbandingan antara kenyataan atas pelayanan yang diterima dengan harapan atas pelayanan yang ingin diterima. (Afrial, 2009). Dalam mengukur sejauh mana kualitas pelayanan publik yang diberikan oleh pemerintah. Dalam mengevaluasi kualitas pelayanan tidak hanya ditentukan oleh pemerintah saja namun juga ditentukan oleh masyarakat, hal ini seperti yang dijelaskan oleh (Barata, 2003) bahwa berbicara mengenai kualitas pelayanan, ukurannya bukan hanya ditentukan oleh pihak yang melayani saja tapi lebih banyak dilayani, karena merekalah yang menimati layanan sehingga dapat mengukur kualitas pelayanan berdasarkan harapan-harapan mereka dalam memenuhi kepuasannya. 
Menurut Parasurament et al terdapat empat dimensi kualitas pelayanan (Tjiptono dan Chandra, 2005) empat dimensi itu mencakup:

a. Reliabilitas (Reliability)

b. Daya Tanggap(Responsiveness)

c. Empati (Emphaty)

d. Bukti Fisik (Tangibles)

$$
\text { Menurut (Sedarmayanti, }
$$

menyatakan bahwa kepuasan adalah tingkat perasaan seseorang setelah membandingkan kinerja (hasil) yang dirasakan dengan harapan. Kepuuasan masyarakat adalah pendapat masyarakat dalam memperoleh pelayanan dari aparatur penyelenggara pelayanan public dengan membandingkan antara harapan dan kebutuhannya.

\section{METODOLOGI PENELITIAN}

Data yang digunakan pada penelitian ini merupakan data primer. Menurut Sugiyono (2012:139) bahwa :"sumber Primer adalah sumber data yang langsung memberikan data kepada pengumpul data dan primer adalah data yang dikumpulkan melalui pihak pertama, biasanya dapat melalui wawancara, dan lainlain.

Teknik pengumpulan data yang digunakan dalam penelitian ini adalah dengan cara membagikan kuesioner kepada responden yang sudah mempunyai KTP yang terdiri atas 21 pertanyaan dengan skala likert nya adalah Sangan Tidak Baik $=1$, Tidak Baik $=2$, Cukup Baik $=3$, Baik $=4$, Sangat Baik $=5$.

\subsection{Analisis Regresi Linier Berganda}

Regresi linier berganda digunakan untuk menganalisis variabel kualitas pelayanan (X) yang terdiri dari bukti fisik $\left(X_{1}\right)$, reliabilitas $\left(X_{2}\right)$, daya tanggap $\left(X_{3}\right)$, dan empati $\left(X_{4}\right)$ berpengaruh terhadap kepuasan masyarakat (Y).

Adapun rumus yang digunakan dalam regresi linier berganda adalah sebagai berikut:

Dimana :

$$
\mathrm{Y}=\mathrm{a}+b_{1} X_{1}+b_{2} X_{2}+b_{3} X_{3}+b_{4} X_{4}
$$

$$
\begin{array}{ll}
\mathrm{Y} & =\text { Kepuasan Masyarakat } \\
\mathrm{a} & =\text { konstanta } \\
\mathrm{b}_{1}, \mathrm{~b}_{2}, \mathrm{~b}_{3}, \mathrm{~b}_{4} & =\text { koefisien regresi } \\
X_{1} & =\text { bukti fisik } \\
X_{2} & =\text { reliabilitas } \\
X_{3} & =\text { daya tanggap } \\
X_{4} & =\text { empati }
\end{array}
$$

Untuk mengetahui signifikansi pengaruh subvariabel bukti fisik, reliabilitas, daya tanggap, dan empati terhadap kepuasan masyarakat dilakukan baik secara simultan dan parsial dengan tingkat kepercayaan sebesar $5 \%$

$$
(\alpha=0,05) .
$$

\section{HASIL DAN PEMBAHASAN \\ 3.1 Deskriptive Statistic}

Tujuan dari tabel descriptive statistiks dibawah ini adalah untuk memberikan gambaran (deskripsi) mengenai suatu data agar data tersaji menjadi mudah dipahami dan informatif bagi yang membaca. Adapun hasil dari statistic deskriptif dalam penelitian ini dapat dilihat pada tabel berikut :

Tabel 1. Descriptive Statistics

\begin{tabular}{lrrrrr}
\hline & N & Min & Max & Mean & \multicolumn{1}{c}{$\begin{array}{c}\text { Std. } \\
\text { Deviation }\end{array}$} \\
\hline x1 & 45 & 12 & 20 & 16,20 & 1,949 \\
x2 & 45 & 13 & 20 & 16,40 & 1,711 \\
x3 & 45 & 36 & 49 & 42,04 & 3,060 \\
x4 & 45 & 2 & 9 & 5,67 & 1,758 \\
Y & 45 & 19 & 30 & 25,89 & 3,304 \\
Valid N & 45 & & & & \\
\hline
\end{tabular}

Berdasarkan tabel 1 statistika Deskriptif diatas dapat diketahui bahwasanya variable $X_{1}$ memiliki nilai terkecil 12 , nilai terbesar 20 , ratarata 16,20 dan standar deviasi sebesar 1,949. Variable $X_{2}$ memiliki nilai terkecil sebesar 13 dan terbesar 20, nilai rata-rata 16,40 dan standar deviasi sebesar 1,71. Variable $X_{3}$ memiliki nilai terkecil sebesar 36 , nilai terbesar 49 , rata-rata 42,04 dan standar deviasi sebesar 3,060. Variable $X_{4}$ nilai terkecil sebesar 2, nilai terbesar sebesar 9, rata-rata sebesar 5,67 dan standar deviasi 1,758. Variabel Y memiliki nilai minimum sebesar 19 dan nilai maksimum sebear 30 dengan nilai rat-rata 25,89 dan nilai standar deviasi 3,304 . Seluruh data variabel $\mathrm{X}$ dan variable $\mathrm{Y}$ valid.

\subsection{Uji Normalitas}

Uji normalitas dapat dilihat melalui analisis grafik yaitu sebagai berikut:

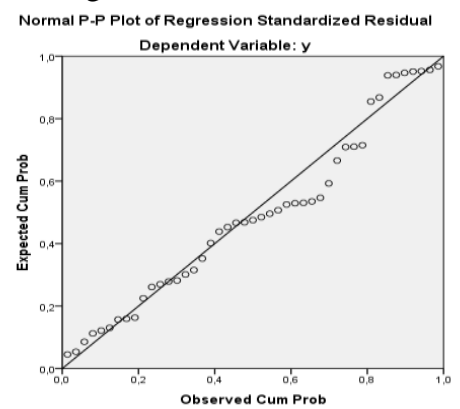

Berdasarkan grafik diatas dapat diketahui 


\section{Gamma-Pi: Jurnal Matematika dan Terapan}

Volume 3 Nomor 2 Desember 2021

bahwasanya data tersebut berdistribusi normal. Penyebaran data tidak jauh dari garis tersebut menandakan bahwasanya data tersebut berdistribusi normal.

\subsection{Uji Reabilitas}

Uji reabilitas digunakan untuk melihat konsistensi jawaban Instrumen dikatakan re liabel (handal) apabila dipergunakan beberapa kali untuk mengukur obyek yang sama akan menghasilkan data yang sama.

Adapun hasil dari uji reliabilitas dalam penelitian ini dapat dilihat pada tabel berikut:

Tabel 2. Uji Reabilitas

\begin{tabular}{cc}
\hline Cronbach's Alpha & $\mathrm{N}$ of Items \\
\hline 0,685 & 5 \\
\hline
\end{tabular}

Uji realibilitas dapat dilakukan secara bersamaan seluruh butir atau item pertanyaan dalam angket penelitian (V.Wiratna Sujarweni.2014). Adapun dasar pengambilan keputusan adalah

1. Jika cronbachs Alfa $>0,60$ maka angket dinyatakan reliable

2. Jika cronbachs Alfa $<0,60$ maka angket dinyatakan tidak reliable

Berdasarkan tabel realibiltas diatas didapatkan nilai Cronbachs Alpha sebesar 0,685 lebih besar daripada 0,60 dan dapat dinyatakan bahwasanya item angket tersebut reliable.

\subsection{Uji Validitas}

Uji validitas adalah suatu ukuran yang menunjukkan kevalidan suatu instrument. Jadi pengujian validitas itu mengacu pada sejauh mana suatu instrument dalam menjalankan fungsi. Adapun hasil dari uji Validitas dalam penelitian ini dapat dilihat pada tabel berikut :

Tabel 3. Uji Validitas Variabel X

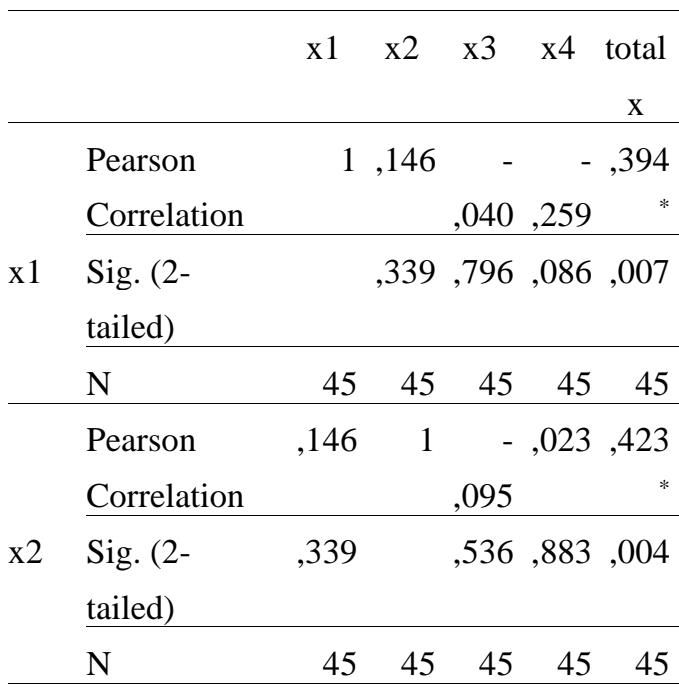

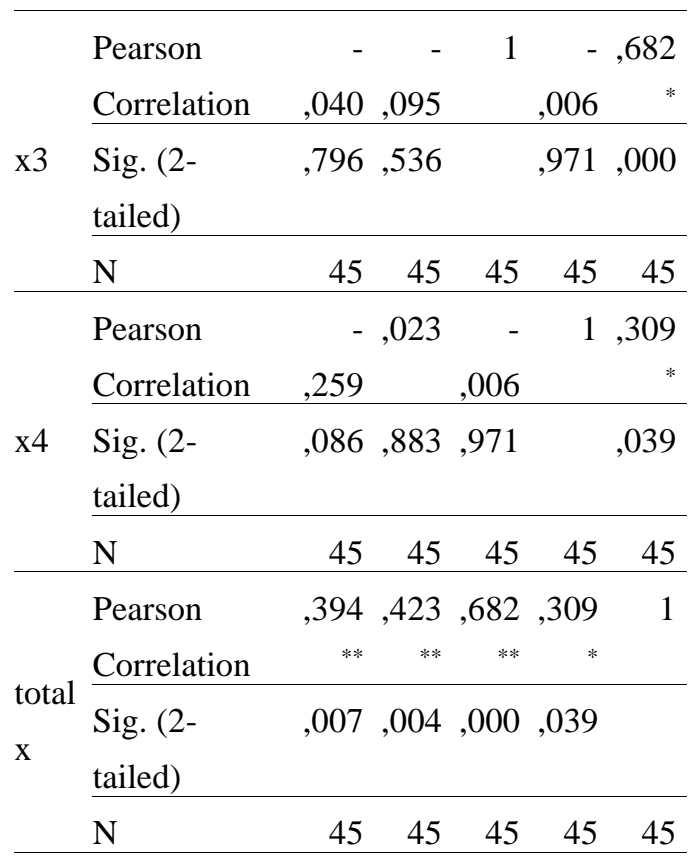

Berdasarkan tabel nilai uji validitas diatas dapat diketahui bahwasanya seluruh variabel $\mathrm{X}$ valid. Nilai r-tabel dengan jumlah responden 45 orang dan taraf signifikansi nya sebesar $95 \%$ yaitu 0,294 . Nilai pearson correlation $X_{1}, X_{2}, X_{3}$ dan $X_{4}$ memiliki nilai $r$ hitung yang lebih besar daripada nilai r-tabel yaitu masing-masing $X_{1}(0,394>$ $0,294), X_{2}(0,423>0,294), X_{3}(0,682>0,294)$ dan $X_{4}(0,309>0,294)$. Seluruh variabel $X$ valid.

\subsection{Uji Multikolinearitas}

Tabel 4. Uji Multikolinearitas

\begin{tabular}{lll}
\hline Model & \multicolumn{2}{l}{ Collinearity Statitics } \\
\cline { 2 - 3 } & Tolerance & VIF \\
\hline X1 & 0,909 & 1,100 \\
X2 & 0,967 & 1,034 \\
X3 & 0,990 & 1,010 \\
X4 & 0,929 & 1,076 \\
\hline
\end{tabular}

Pada tabel uji multikolinearitas dapat dilihat:
Nilai Tolerance nya
a. $\mathrm{X} 10,909>0,100$
b. $\mathrm{X} 20,967>0,100$
c. $\mathrm{X} 30,990>0,100$
d. $\mathrm{X} 40,929>0,100$
Nilai VIP
a. $\mathrm{X} 11,100<10,00$
b. $\mathrm{X} 21,034<10,00$
c. $\mathrm{X} 31,010<10,00$
d. $\mathrm{X} 41,076<10,00$ 
Setelah melihat nilai tolerance dan VIF pada tabel diatas maka dapat diambil keputusan bahwasanya tidak terjadi multikolinearitas pada model regresi tersebut.

\subsection{Uji Heteroskesdasitas}

Uji Heteroskesdasitas dapat dilihat pada tabel dibawah ini:

Tabel 5. Uji Heteroskesdasitas

\begin{tabular}{|c|c|c|c|c|c|c|}
\hline \multicolumn{2}{|c|}{ Model } & \multicolumn{2}{|c|}{$\begin{array}{l}\text { Unstandardized } \\
\text { Coefficients }\end{array}$} & \multirow{2}{*}{$\begin{array}{c}\begin{array}{c}\text { Standardize } \\
\mathrm{d} \\
\text { Coefficients }\end{array} \\
\text { Beta }\end{array}$} & \multirow[t]{2}{*}{$\mathrm{t}$} & \multirow[t]{2}{*}{ Sig. } \\
\hline & & B & Std. Error & & & \\
\hline \multirow{5}{*}{1} & (Constant) & 6,584 & 4,929 & & 1,336 & , 189 \\
\hline & $\mathrm{x} 1$ &,- 057 & ,134 &,- 069 &,- 423 & 675 \\
\hline & $\bar{x} 2$ &,- 169 & , 148 &,- 179 & $-1,139$ & ,261 \\
\hline & $\mathrm{x} 3$ &,- 016 &, 082 &,- 031 &,- 196 & ,846 \\
\hline & $\mathrm{x} 4$ &,- 043 &, 147 &,- 047 &,- 294 & ,771 \\
\hline
\end{tabular}

Pada tabel 5 dapat dilihat bahwa:

a. Nilai sig variable $\mathrm{x} 1$ adalah $0,675>0,05$

b. Nilai sig variable $\mathrm{x} 2$ adalah $0,261>0,05$

c. Nilai sig variable $x 3$ adalah $0,846>0,05$

d. Nilai sig variable $x 4$ adalah $0,771>0,05$
Karena nilai sig. lebih besar daripada 0,05 maka dapat disimpulkan tidak terjadi Heteroskesdasitas.

\subsection{Hasil Analisis Regresi Linier berganda}

Tabel 6. Koefisien Analisis regresi linier berganda

\begin{tabular}{|c|c|c|c|c|c|}
\hline \multirow[t]{2}{*}{ Model } & \multicolumn{2}{|c|}{ Unstandardized Coefficients } & $\begin{array}{l}\text { Standardized } \\
\text { Coefficients }\end{array}$ & \multirow[t]{2}{*}{$\mathrm{t}$} & \multirow[t]{2}{*}{ Sig. } \\
\hline & $\mathrm{B}$ & Std. Error & Beta & & \\
\hline \multirow{2}{*}{ (Constant) } & 2,99 & 8,024 & & ,373 & 0,07 \\
\hline & 1 & & & & \\
\hline \multirow{2}{*}{$1 \frac{\mathrm{x} 1}{\mathrm{x} 2}$} &, 166 &, 218 & ,098 &, 762 & 0,040 \\
\hline & ,983 & ,241 &, 509 & 4,076 & 0,000 \\
\hline$\underline{x} 3$ & ,008 &, 133 & ,007 &, 059 & 0,095 \\
\hline $\mathrm{x} 4$ & 661 & ,239 & ,352 & 2,760 & 0,009 \\
\hline
\end{tabular}

Berdasarkan Tabel 6 diatas didapatkan persamaan regresi sebagai berikut:

$$
\begin{gathered}
Y=2,991+0,166 \times 1+0,983 \times 2+0,08 \times 3 \\
+0,661 \times 4+\varepsilon
\end{gathered}
$$

1. Kepuasan masyarakat akan meningkat sebesar 0,166 satuan untuk setiap tambahan satu satuan $\mathrm{x} 1$

2. Kepuasan masyarakat akan meningkat sebesar 0,983 satuan untuk setiap tambahan satu satuan $\mathrm{x} 2$

3. Kepuasan masyarakat akan meningkat sebesar 0,08 satuan untuk setiap tambahan satu satuan $\mathrm{x} 3$

4. Kepuasan masyarakat akan meningkat sebesar 0,661 satuan untuk setiap tambahan satu satuan $\mathrm{x} 4$
Untuk mengetahui besar kontribusi variabel kualitas pelayanan (X) terhadap variabel Kepuasan masyarakat (Y) digunakan nilai R2 . Nilai R2 seperti Tabel dibawah ini:

\subsubsection{Uji Koefisien Korelasi dan Determinasi}

Tabel 7. Koefisien Korelasi dan Determinasi

Model R R Square Adjusted R Std. Error Square of the

\begin{tabular}{|c|c|c|c|c|}
\hline 1 & ,630 & ,396 & ,336 & 2,692 \\
\hline
\end{tabular}
Estimate 


\section{Gamma-Pi: Jurnal Matematika dan Terapan}

Volume 3 Nomor 2 Desember 2021

Dari hasil analisis pada Tabel 7 diperoleh hasil R square (koefisien determinasi) sebesar 0,396. Artinya bahwa $39,6 \%$ variabel Kepuasan masyarakat akan dipengaruhi oleh variabel kualitas pelayanan. Sedangkan sisanya $60,4 \%$ variabel Kepuasan masyarakat akan dipengaruhi oleh variabel-variabel yang lain yang tidak dibahas dalam penelitian ini. Selain koefisien determinasi juga didapat koefisien korelasi (R) sebesar 0,630.

\subsubsection{Uji Simultan Signifikan (Uji-F)}

Uji statistik $F$ bertujuan untuk mengetahui apakah kualitas pelayanan (X) yang terdiri dari bukti langsung (X1), reliabilitas (X2), daya tanggap (X3), dan empati (X4) secara simultan atau bersama-sama mempengaruhi kepuasan masyarakat $(\mathrm{Y})$.

Dengan hipotesis untuk uji $\mathrm{F}$ sebagai berikut:

$H_{0}=$ Variabel bukti langsung $\left(X_{1}\right)$, Variabel realibilitas $\left(X_{2}\right)$, Variabel daya tanggap $\left(X_{3}\right)$, Variabel empati $\left(X_{4}\right)$ secara simultan tidak berpengaruh terhadap kepuasan masyarakat (Y).

$H_{1}=$ Variabel bukti langsung $\left(X_{1}\right)$, Variabel realibilitas $\left(X_{2}\right)$, Variabel daya tanggap $\left(X_{3}\right)$, Variabel empati $\left(X_{4}\right)$ secara simultan berpengaruh terhadap kepuasan masyarakat (Y).

Jika $F_{\text {hitung }}>F_{\text {tabel }}$, maka $H_{0}$ ditolak dan $H_{1}$ diterima. Hal ini menunjukkan bahwa Variabel bukti langsung $\left(X_{1}\right)$, Variabel realibilitas $\left(X_{2}\right)$, Variabel daya tanggap $\left(X_{3}\right)$, Variabel empati $\left(X_{4}\right)$ secara simultan tidak berpengaruh terhadap kepuasan masyarakat (Y).

Jika $F_{\text {hitung }}<F_{\text {tabel }}$, maka $H_{0}$ diterima dan $H_{1}$ ditolak. Hal ini menunjukkan bahwa Variabel bukti langsung $\left(X_{1}\right)$, Variabel realibilitas $\left(X_{2}\right)$, Variabel daya tanggap $\left(X_{3}\right)$, Variabel empati $\left(X_{4}\right)$ secara simultan berpengaruh terhadap kepuasan masyarakat (Y). Hasil uji F simultan dapat dilihat pada tabel 8.

Tabel 8. Hasil uji F

\begin{tabular}{|c|c|c|c|c|c|}
\hline Model & $\begin{array}{l}\text { Sum of } \\
\text { Squares }\end{array}$ & Df & $\begin{array}{c}\text { Mean } \\
\text { Square }\end{array}$ & F & Sig. \\
\hline $\begin{array}{l}\text { Regres } \\
\text { sion } \\
\end{array}$ & 190,496 & 4 & 47,624 & $\begin{array}{r}6,57 \\
0 \\
\end{array}$ & $\begin{array}{r}, 000 \\
\mathrm{~b}\end{array}$ \\
\hline $\begin{array}{l}\text { Residu } \\
\text { al }\end{array}$ & 289,949 & 40 & 7,249 & & \\
\hline Total & 480,444 & 44 & & & \\
\hline
\end{tabular}

$F_{\text {tabel }}=(\mathrm{k} ; \mathrm{n}-\mathrm{k})$

$$
\begin{aligned}
& =(4 ; 45-4) \\
& =(4 ; 41) \\
& =2,60
\end{aligned}
$$

Berdasarkan dari tabel 8 uji anova dan $\mathrm{F}$ dengan nilai sig pada table anova yaitu sebesar 6,570, sedangkan F tabel adalah sebesar 2,60. Karena F hitung lebih besar dari $F$ tabel yaitu 6,570 lebih besar dari 2,60 dan nilai Sig. F $(0,000)$ lebih kecil dari $\alpha=$ 0.05 maka model analisis regresiya signifikan. Hal ini berarti H0 ditolak sehingga dapat disimpulkan bahwa secara simultan variabel kepuasan masyarakat dapat dipengaruhi secara signifikan oleh variabel kualitas pelayanan yang terdiri dari tangible (X1), reliability (X2), responsicenses (X3), dan empati (X4).

\subsubsection{Uji Signifikan Parsial (Uji T)}

Uji T ini bertujuan untuk mengetahui apakah kualitas pelayanan (X) yang terdiri dari bukti langsung (X1), reliabilitas (X2), daya tanggap (X3), dan empati (X4), secara parsial atau sendiri mempengaruhi kepuasan masyarakat $(\mathrm{Y})$.

Dengan hipotesis untuk uji $\mathrm{T}$ sebagai berikut : $H_{0}=$ Variabel bukti langsung $\left(X_{1}\right)$, Variabel realibilitas $\left(X_{2}\right)$, Variabel daya tanggap $\left(X_{3}\right)$, Variabel empati $\left(X_{4}\right)$ secara parsial tidak berpengaruh terhadap kepuasan masyarakat (Y) $H_{1}=$ Variabel bukti langsung $\left(X_{1}\right)$, Variabel realibilitas $\left(X_{2}\right)$, Variabel daya tanggap $\left(X_{3}\right)$, Variabel empati $\left(X_{4}\right)$ secara parsial berpengaruh terhadap kepuasan masyarakat (Y).

Jika $t_{\text {hitung }}>t_{\text {tabel }}$, maka $H_{0}$ ditolak dan $H_{1}$ diterima. Hal ini menunjukkan bahwa Variabel bukti langsung $\left(X_{1}\right)$, Variabel realibilitas $\left(X_{2}\right)$, Variabel daya tanggap $\left(X_{3}\right)$, Variabel empati $\left(X_{4}\right)$ secara parsial tidak berpengaruh terhadap kepuasan masyarakat (Y).

Jika $t_{\text {hitung }}<t_{\text {tabel }}$, maka $H_{0}$ diterima dan $H_{1}$ ditolak. Hal ini menunjukkan bahwa Variabel bukti langsung $\left(X_{1}\right)$, Variabel realibilitas $\left(X_{2}\right)$, Variabel daya tanggap $\left(X_{3}\right)$, Variabel empati $\left(X_{4}\right)$ secara parsial berpengaruh terhadap kepuasan masyarakat

\begin{tabular}{|c|c|c|c|c|c|c|}
\hline \multirow{2}{*}{\multicolumn{2}{|c|}{ Model }} & \multicolumn{2}{|c|}{$\begin{array}{c}\text { Unstandardized } \\
\text { Coefficients }\end{array}$} & \multirow{2}{*}{$\begin{array}{c}\text { Standardized } \\
\text { Coefficients }\end{array}$} & \multirow[t]{2}{*}{$\mathrm{t}$} & \multirow[t]{2}{*}{ Sig. } \\
\hline & & $\mathrm{B}$ & Std. Error & & & \\
\hline \multirow{5}{*}{1} & $\begin{array}{l}\text { (Cons } \\
\operatorname{tant})\end{array}$ & 2,991 & 8,024 & &, 373 & 0,07 \\
\hline & $\mathrm{x} 1$ & , 166 & ,218 & ,098 & ,762 & 0,040 \\
\hline & $\mathrm{x} 2$ & ,983 & ,241 & ,509 & 4,076 & 0,000 \\
\hline & $\mathrm{x} 3$ & ,008 & ,133 & ,007 &, 059 & 0,095 \\
\hline & $\mathrm{x} 4$ & 661, & 239, & ,352 & 2,760 & 0,009 \\
\hline
\end{tabular}
(Y). Hasil uji parsial T dapat dilihat pada tabe 9.

Tabel 9. Uji Parsial T 


\section{Gamma-Pi: Jurnal Matematika dan Terapan}

Volume 3 Nomor 2 Desember 2021

Berdasarkan pada Tabel 9 didapatkan persamaan regresi sebagai berikut:

a. Pengaruh antara X1 (tangible) dengan Y (Kepuasan masyarakat) menunjukkan t hitung $=0,762$ sedangkan $\mathrm{t}$ tabel sebesar 2,021. Karena t hitung lebih besar dari t tabel yaitu 0,762 lebih kecil dari 2,021 maka pengaruh X1 (tangible) terhadap Kepuasan masyarakat tidak signifikan. Hal ini berarti H0 tidak ditolak sehingga dapat disimpulkan bahwa secara parsial Kepuasan masyarakat begitu dipengaruhi secara signifikan oleh tangible.

b. Pengaruh antara X2 (reliability) dengan Y (Kepuasan masyarakat) menunjukkan $\mathrm{t}$ hitung $=4,076$, sedangkan $\mathrm{t}$ tabel adalah sebesar 2,021. Karena t-hitung lebih besar dari t tabel yaitu 4,076 lebih besar dari 2,021 . Hal ini berarti H0 ditolak sehingga dapat disimpulkan bahwa secara parsial Kepuasan masyarakat dipengaruhi secara signifikan oleh reliability.

c. Pengaruh antara X3 (responsiveness) dengan $\mathrm{Y}$ (Kepuasan masyarakat) menunjukkan t hitung $=0,059$, sedangkan t-tabel adalah sebesar 2,021. Karena t-hitung lebih kecil dari t tabel yaitu 0,095 lebih kecil dari 2,021 . Hal ini berarti H0 tidak ditolak sehingga dapat disimpulkan bahwa secara parsial Kepuasan masyarakat tidak dipengaruhi secara signifikan oleh responsicenses.

d. Pengaruh antara X4 (empati) dengan Y (Kepuasan masyarakat) menunjukkan t hitung $=2,760$, sedangkan t-tabel adalah sebesar 2,021. Karena t hitung lebih besar dari t-tabel yaitu 2,760 lebih besar 2,021. Hal ini berarti H0 ditolak sehingga dapat disimpulkan bahwa secara parsial Kepuasan masyarakat dipengaruhi secara signifikan oleh empati.

\section{KESIMPULAN}

Berdasarkan hasil dapat disimpulkan bahwa :

1. Dari analisis, didapat koefisien determinasi sebesar 0,396. Artinya bahwa 39,6\% variabel Kepuasan Masyarakat akan dipengaruhi oleh variabel kualitas pelayanan. Sedangkan sisanya $60,4 \%$ Kota langsa harus meningkatkan kualitas. Pelayanan. Variabel Kepuasan Masyarakat akan dipengaruhi oleh variabel variabel yang lain yang tidak dibahas dalam penelitian ini. Selain koefisien determinasi juga dapat koefisien korelasi (R) sebesar 0,630.

2. Kualitas pelayanan yang terdiri dari realibilitas dan empati secara simultan berpengaruh terhadap kepuasan masyarakat yang menerima pelayanan perekaman KTP. Sedangkan tangible dan responsicenses secara simultan tidak berpengaruh terhadap kepuasan masyarakat yang menerima pelayanan perekaman KTP.

\section{DAFTAR PUSTAKA}

Afrial, R. 2009. "Kualitas pelayanan publik kecamatan sebuah perubahan kedudukaan dan fungsi camat sebagai perangkat daerah". Jurnal administrasi.

Arikunto, S. 2013. Prosedur Penelitian, suatu pendekatan praktik. Jakarta: Rineka Cipta

Barata, A.A. 2003. Dasar-Dasar pelayanan prima. Jakarta, PT Elex Media Komputindo.

Dwiyanto. 1995. Kepuasan Masyarakat Publik. Jakarta, PT. Gramedia Pustaka Utama.

Dyah Nirmala Arun Janie, S.E., M.Si, 2012. Statistik Deskripritif \& Regresi Linier Berganda dengan SPSS. Semarang University Press, ISBN : 978-602-9019-988.

Hardiansyah. 2011. Kualitas Pelayanan Publik. Gava Media, Yogyakarta.

Sarwono, Jonathan. 2006. Metode Penelitian Kuantitatif \& Kualitatif. Yogyakarta: Penerbit Graha Ilmu.

Sedarmayanti, 2007.Good Governance (pemerintahan yang baik) dan Good Corporate Governance (pengelolaan perusahaan yang baik). Jilid III. Mandar Maju, Bandung.

Sudarmanto, R.Gunawan. 2005. Analisis Regresi Linier Berganda dengan SPSS. Graha ilmu Yogyakarta.

Sugiyono. 2012. Metode penelitian kuantitatif kualitatif dan R\&D. Bandung: Alfabeta.

Tjiptono, F \& Chandra, G. 2005.Service, Quality \& Satisfaction. Yogyakarta.

Zuldafial. 2012. Penelitian Kuantitatif. Yogyakarta: Media Perkasa 